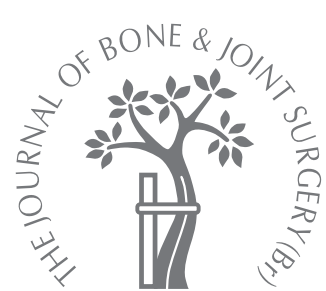

R. Itayem,

A. Arndt,

D. J. W. McMinn,

J. Daniel,

A. Lundberg

From the Karolinska Institute, Stockholm, Sweden

n. Itayem, MD, Consultant Orthopaedic Surgeon

A. Arndt, PhD, Associate

Professor

A. Lundberg, MD, PhD,

Associate Professor

Department of Orthopaedic

Surgery

Karolinska Institute, Karolinska

University Hospital, 14186

Stockholm, Sweden.

D. J. W. McMinn, FRCS,

Consultant Orthopaedic

Surgeon

J. Daniel, FRCS, Director of

Research

The McMinn Centre, 25

Highfield Road, Edgbaston,

Birmingham B15 3DP, UK.

Correspondence should be sent to $\mathrm{Dr}$ R. Itayem at Department

of Orthopaedic Surgery, Visby

Hospital, 62184 Visby, Sweden;

e-mail:

raed.itayem@hsf.gotland.se

()2007 British Editorial Society of Bone and Joint Surgery doi:10.1302/0301-620X.89B9. $18367 \$ 2.00$

$J$ Bone Joint Surg $[\mathrm{Br}]$ 2007;89-B:1140-3.

Received 6 July 2006; Accepted after revision 23 April 2007

\title{
A five-year radiostereometric follow-up of the Birmingham Hip Resurfacing arthroplasty
}

\begin{abstract}
The early designs of hip resurfacing implants suffered high rates of early failure, making it impossible to obtain valuable mid-term radiostereophotogrammetric (RSA) results. The metal-on-metal Birmingham Hip Resurfacing arthroplasty has shown promising mid-term results and we present here the first mid-term RSA analysis of a hip resurfacing implant.

The analysis was performed in 19 hips at five years post-operatively. The mean acetabular component translation and rotation, and femoral component translation were compared with the previous RSA measurements at two and six months, and one and two years.
\end{abstract}

There was no statistical significance ( $t$-test, $p \leq 0.05$ ) between these consecutive movements, indicating the mid-term stability of the implant.

The concept of hip resurfacing using a polyethylene acetabular component and a metal femoral head, which gained popularity in the $1970 \mathrm{~s},{ }^{1-7}$ was abandoned because of high rates of failure related to debris from the polyethylene bearing. ${ }^{8}$ Modern cobaltchrome metal-on-metal resurfacing arthroplasty with cemented femoral and uncemented acetabular components has been used since the late 1980s. ${ }^{9}$ The Birmingham Hip Resurfacing (BHR) (Midland Medical Technologies, now Smith and Nephew, Warwick, United Kingdom) arthroplasty, which was introduced in 1997, has produced promising short- and mid-term clinical results $^{10-12}$ infusing new interest in hip resurfacing, especially for young and active patients.

Hip resurfacing carries the risk of early or late femoral neck fracture or avascular necrosis of the femoral head. These can be visualised in conventional radiographs. However, a small degree of distal migration of the femoral component can remain undetected. In total hip replacement (THR), distal migration of the femoral component is the most significant movement pattern determining the longevity of the prosthesis. ${ }^{13}$

Radiostereophotogrammetric analysis (RSA) is a tool to assess the migration of implants, with a detection threshold of translation up to ten times better than conventional radiography. ${ }^{14}$ The application of RSA in studying migration patterns is invaluable. ${ }^{15,16}$
A two-year RSA stability analysis of the BHR implant has been published. ${ }^{17,18}$ The present study reports the mid-term five-year RSA results for the BHR arthroplasty.

This is the first study to describe mid-term hip resurfacing RSA analysis, after the first generation of polyethylene with metal resurfacing designs suffered from high early failure rates.

\section{Patients and Methods}

We report 19 consecutive male patients who underwent treatment with a BHR implant. A bilateral procedure was undertaken in one patient, so the total number of prostheses studied was 20.

At the five-year follow-up one patient had died from an unrelated cause and was not included in the analysis, leaving 19 hips (18 patients) available for evaluation. All operations were performed by the same surgeon (DJWM). The implants were equipped with tantalum markers on titanium towers (Fig. 1). During the operation, six to eight additional markers per segment were introduced into the pelvis and femur (Fig. 1).

Radiological examinations were performed at two and six months, and at one, two years and five years post-operatively. The data obtained at five years were analysed using mRSA software (RSA Biomedical, Umeå, Sweden). The centre of the acetabular component was considered to approximate to the centre of the femoral head with sufficient accuracy 


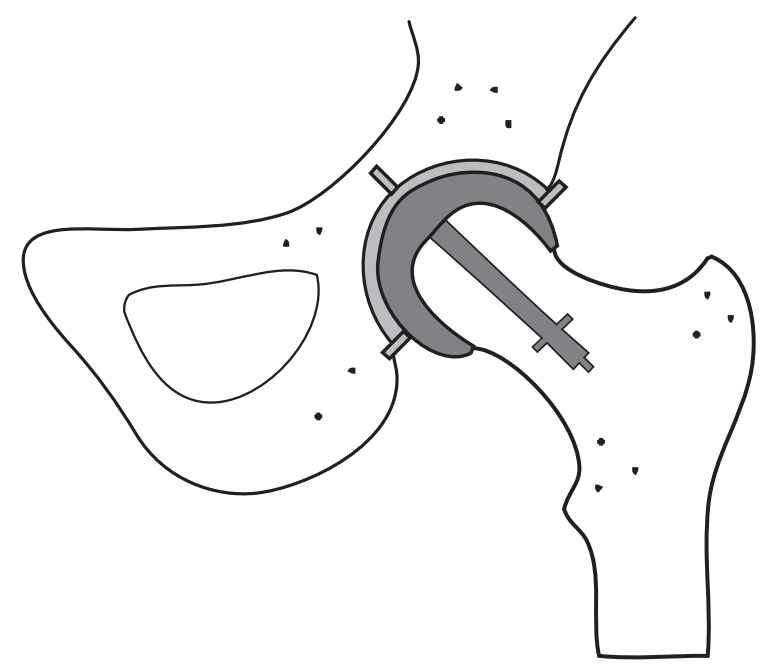

Fig. 1

A diagram of the Birmingham Hip Resurfacing implant showing tanatalum markers in the femur and pelvis as well as mounted on the femoral and acetabular components.

to allow its migration patterns to be calculated from the markers which had been fixed to the femoral component as previously described ${ }^{17}$ Because of the absence of significant rotation of the femoral component in all measurements during the study, we present only the values of the translation of the centre of the femoral head as measurements of the migration of the femoral component in relation to the femur.

A problem in analysing migration of metal-on-metal resurfacing femoral components arises from limitations of positioning of the X-ray tube imposed by the need to identify the polar acetabular markers in two views. ${ }^{17}$ Our previous experience suggests that the expected errors along the anteroposterior axis are approximately twice those observed in relation to the transverse and vertical axes. ${ }^{17}$

The parameters calculated to describe consecutive RSA examinations are the mean error (the mean difference in measured position of each marker in a segment, in relation to the reference examination) and the condition number (a measure of the spatial spread of the markers in a segment, where a very high value indicates that the markers are close to forming a straight line in space, which precludes measurements of segment rotation). The mean error and condition numbers were calculated for each examination, and when the condition number exceeds 200, we present only the translation data relating to the corresponding segment or point. Differences in rotation and translation between two months and two years, as well as between two months and five years, were tested using Student's $t$-test for dependent samples. The initial measurement for statistical analysis was taken two months post- operatively to allow time for the incorporation of the implant. The level of significance was set at $\mathrm{p}<0.05$.

\section{Results}

The centre of the femoral head could be calculated in all patients. The mean values for translation of the femoral components were low (Table I). The rotation data for the acetabular component in three subjects were excluded because of condition numbers exceeding 200. In these three patients translation of this component was calculated only by the polar marker, as the other two markers were insufficiently defined. Another patient was excluded from all acetabular component calculations because of missing pelvis segment data.

The mean (SD) translation of the acetabular component at five years was $0.00 \mathrm{~mm}$ (SD 0.19) medially, $0.06 \mathrm{~mm}$ (SD 0.17) superiorly and $0.11 \mathrm{~mm}$ (SD 0.26) anteriorly (Table II). The mean translation of the polar acetabular marker in the three patients with incomplete data was 0.23 $\mathrm{mm}$ (SD 0.30) medially, $0.24 \mathrm{~mm}$ (SD 0.46) inferiorly and $0.30 \mathrm{~mm}$ (SD 0.26) anteriorly. The mean rotation at five years was $0.52^{\circ}\left(\mathrm{SD} 0.86^{\circ}\right)$ in relation to the transverse axis, but without a statistical significance ( $t$-test, $\mathrm{p}=0.057$ ) compared with the two-month follow-up measurements. Rotations in relation to the other axes were not statistically significant at either interval.

\section{Discussion}

Implant migration is considered to be an important indicator of failure. ${ }^{13}$ At two years post-operatively, RSA studies of THRs have been accepted as prognostic of longterm survival, based on empirically-based experience of the prosthesis migration pattern. ${ }^{13}$ However, in surface replacement, no such RSA analyses exist, owing to the failure of the early designs, and thus there is no available information on the parameters that might indicate failure of the prosthesis.

With increased interest in hip resurfacing it is important to report and analyse RSA findings. Although absence of migration in RSA studies does not guarantee good longterm results, it can usually be expected to be a favourable prognostic factor. At two years pre-operatively RSA studies of the BHR implant have shown no statistically significant migration of the components. ${ }^{17,18}$

In our previous study, ${ }^{17}$ translations in the transverse and vertical axes of the femoral neck were measured as they were considered possible directions of subsidence of the femoral component. These values were lower than those usually seen in RSA studies of THRs. ${ }^{13,19}$ However, migration along the vertical axis was slightly increased by the end of the study, and in some measurements the pattern of posterior translation exceeded the detection of migration. ${ }^{17}$ In order to clarify the significance of this observation, this study calculated the migration of the femoral component along three axes. The new measurements did not detect any distal migration. The relatively 
Table I. Mean (SD) translation values of the femoral component. The translation calculations include all 18 patients at the five-year follow-up

\begin{tabular}{|c|c|c|c|c|c|c|c|c|c|}
\hline & \multirow[b]{2}{*}{ Axis } & \multicolumn{5}{|c|}{ Time interval after surgery } & \multirow[b]{2}{*}{$\mathbf{p}^{*}$} & \multirow[b]{2}{*}{$\mathbf{p}^{\dagger}$} & \multirow[b]{2}{*}{$\mathrm{Cl}^{\ddagger}$} \\
\hline & & 2 mths & 6 mths & $1 \mathrm{yr}$ & 2 yrs & 5 yrs & & & \\
\hline \multirow{3}{*}{$\begin{array}{l}\text { Femoral component } \\
\text { translation }(\mathrm{mm})\end{array}$} & Transverse $(\mathrm{X})$ & $0.01(0.24)$ & $-0.04(0.27)$ & $-0.05(0.26)$ & $-0.08(0.31)$ & $-0.15(0.34)$ & 0.288 & 0.062 & -0.30 to 0.00 \\
\hline & Vertical (Y) & $0.06(0.14)$ & $0.07(0.16)$ & $0.03(0.13)$ & $-0.01(0.16)$ & $0.00(0.25)$ & 0.769 & 0.930 & -0.10 to 0.11 \\
\hline & Anteroposterior (Z) & $0.07(0.64)$ & $-0.01(0.70)$ & $-0.10(0.55)$ & $0.10(0.69)$ & $0.05(0.56)$ & 0.684 & 0.677 & -0.19 to 0.31 \\
\hline
\end{tabular}

Table II. Mean (SD) translation and rotation values of the acetabular component. The translation calculations at five years are from 18 patients (the measurements from the patients were from one marker and were excluded from the main calculation). The rotational analysis at five years included 15 patients (three patients had condition numbers exceeding 200 and were excluded)

\begin{tabular}{|c|c|c|c|c|c|c|c|c|c|}
\hline & \multirow[b]{2}{*}{ Axis } & \multicolumn{5}{|c|}{ Time interval after surgery } & \multirow[b]{2}{*}{$\mathbf{p}^{*}$} & \multirow[b]{2}{*}{$\mathbf{p}^{\dagger}$} & \multirow[b]{2}{*}{$\mathrm{Cl}^{\ddagger}$} \\
\hline & & $2 \mathrm{mths}$ & 6 mths & $1 \mathrm{yr}$ & 2 yrs & 5 yrs & & & \\
\hline \multirow{3}{*}{$\begin{array}{l}\text { Acetabular component } \\
\text { translation }(\mathrm{mm})\end{array}$} & Transverse (X) & $-0.01(0.09)$ & $0.01(0.11)$ & $0.02(0.17)$ & $-0.02(0.15)$ & $-0.00(0.19)$ & 0.624 & 0.800 & -0.10 to 0.09 \\
\hline & Vertical $(Y)$ & $0.08(0.09)$ & $0.08(0.12)$ & $0.06(0.12)$ & $0.05(0.12)$ & $0.06(0.17)$ & 0.163 & 0.430 & -0.03 to -0.15 \\
\hline & Anteroposterior $(\mathrm{Z})$ & $0.05(0.13)$ & $0.11(0.23)$ & $-0.00(0.25)$ & $-0.03(0.19)$ & $0.11(0.26)$ & 0.088 & 0.341 & -0.02 to 0.24 \\
\hline \multirow{3}{*}{$\begin{array}{l}\text { Acetabular component } \\
\text { rotation }\left({ }^{\circ}\right)\end{array}$} & Transverse $(\mathrm{X})$ & $0.06(0.34)$ & $0.11(0.41)$ & $0.09(0.50)$ & $0.23(0.55)$ & $0.52(0.86)$ & 0.067 & 0.057 & 0.08 to 0.95 \\
\hline & Vertical (Y) & $0.07 \quad(0.32)$ & $-0.05(0.27)$ & $-0.02(0.36)$ & $0.10(0.25)$ & $0.22(0.49)$ & 0.659 & 0.199 & -0.02 to 0.47 \\
\hline & Anteroposterior (Z) & $0.03(0.17)$ & $0.10(0.24)$ & $0.10(0.32)$ & $0.06(0.28)$ & $-0.09(0.51)$ & 0.442 & 0.467 & -0.34 to 0.17 \\
\hline
\end{tabular}

higher values in the anteroposterior axis correlate to the values seen in the two-year follow-up measurements (Table I), which allows us to assume that we observed higher error values in this direction ${ }^{17}$ and that there is no significant migration pattern.

The acetabular component migration values in this study differ slightly from those presented previously ${ }^{17}$ for three reasons. First, a patient died and was excluded from the present statistical calculations. Secondly, a patient who was previously excluded from the calculations of acetabular rotation was now included, and finally the updated software used for analysis has a higher level of accuracy. Despite these differences, there are no statistically significant changes in either rotation or translation for the acetabular component at the fiveyear follow-up.

In several previously-studied implants, particularly uncemented ones, a pattern of early migration along the loading direction was observed in the early post-operative measurement, which subsequently stopped. ${ }^{13}$ There were no such detectable migrations in our study, although the pattern of vertical migration of the acetabular component indicates that this behaviour may in fact be present. Our study shows that migration values at five years were small compared with earlier studies of uncemented acetabular components and cemented femoral components in THRs and are comparable with our ear- lier published data. ${ }^{17,18}$ Although this does not ensure the longevity of the implant, it does indicate that medium-term migration is not an expected mode of failure.

\section{Supplementary Material}

$\because$ Supplementary graphs showing implant migration C are available with the electronic version of this article on our website at www.jbjs.org.uk

No benefits in any form have been received or will be received from a commercial party related directly or indirectly to the subject of this article.

\section{References}

1. Paltrinieri M, Trentani C. Modification of the hip arthroprosthesis. Chir Organi Mov 1971;60:85-92 (in Italian).

2. Amstutz H, Graff-Radford A, Gruen T, Clarke IC. Tharies surface replacements: a review of the first 100 cases. Clin Orthop 1978;134;87-101.

3. Capello W, Ireland P, Trammell T, Eicher P. Conservative total hip arthroplasty: a procedure to conserve bone stock. Part I: analysis of sixty-six patients. Part II: analysis of failure. Clin Orthop 1978;134:59-74.

4. Furuya K, Tsuchiya H, Kawachi S. Socket-cup arthroplasty. Clin Orthop 1978;134:41-4.

5. Tanaka S. Surface replacement of the hip joint. Clin Orthop 1978;134:75-9.

6. Wagner H. Surface replacement arthroplasty of the hip. Clin Orthop 1978;134:10230 .

7. Freeman M, Cameron H, Brown G. Cemented double cup arthroplasty of the hip: a 5 year experience with the ICLH prosthesis. Clin Orthop 1978;134:45-52.

8. Amstutz H. Surface replacement arthroplasty. In: Amstutz H, ed. Hip arthroplasty. Edinburgh: Churchill-Livingstone, 1991:295-332.

9. McMinn D, Treacy R, Lin K, Pynsent P. Metal on metal surface replacement of the hip: experience of the McMinn prosthesis. Clin Orthop 1996;329(Suppl):89-98. 
10. Daniel J, Pynsent P, McMinn D. Metal on metal resurfacing of the hip in patients under the age of 55 years with osteoarthritis. J Bone Joint Surg [Br] 2004;86-B:177-84.

11. Treacy RB, McBryde CW, Pynsent PB. Birmingham hip resurfacing arthroplasty: a minimum follow-up of five years. J Bone Joint Surg [Br] 2005;87-B:167-70.

12. Pollard TC, Baker RP, Eastaugh-Waring SJ, Bannister GC. Treatment of the young active patient with osteoarthritis of the hip: a five- to seven-year comparison of the hybrid total hip arthroplasty and metal-on-metal resurfacing. J Bone Joint Surg [Br] 2006;88-B:592-600.

13. Kärrholm J, Herberts $\mathbf{P}$, Hultmark $\mathbf{P}$, et al. Radiostereometry of hip prostheses: review of methodology and clinical results. Clin Orthop 1997;344:94-110.

14. Malchau H, Kärrholm J, Wang YX, Herberts $\mathbf{P}$. Accuracy of migration analysis in hip arthroplasty: digitized and conventional radiography compared to radiostereometry in 51 patients. Acta Orthop Scand 1995;66:418-24.
15. Hauptfleisch J, Glyn-Jones S, Beard DJ, Gill HS, Murray DW. The premature failure of the Charnley Elite-Plus stem: a confirmation of RSA predictions. J Bone Joint Surg [Br] 2006;88-B:179-83.

16. Derbyshire B, Porter ML. A study of the Elite Plus femoral component using radiostereometric analysis. J Bone Joint Surg [Br] 2006;89-B:730-5.

17. Itayem R, Arndt A, Nistor L, McMinn D, Lundberg A. Stability of the Birmingham hip resurfacing arthroplasty at two years. J Bone Joint Surg [Br] 2005;87B:158-62.

18. Glyn-Jones S, Gill HS, McLardy-Smith P, Murray DW. Roentgen stereophotogrammetric analysis of the Birmingham hip resurfacing arthroplasty: a two-year study. J Bone Joint Surg [Br] 2004;86-B:172-6.

19. Kärrholm J, Borssen B, Löwenhielm G, Snorrason F. Does early migration of femoral stem prosthesis matter: 4-7 year stereophotogrammetric follow-up of 84 cemented prostheses. J Bone Joint Surg [Br] 1994;76-B:912-17. 